OPEN ACCESS

Edited by:

Rudy Valentine,

lowa State University, United States

Reviewed by:

Wagner Luis Ripka,

Federal Technological University

of Paraná, Brazil

Spyridon Kanellakis,

Harokopio University, Greece

*Correspondence:

Carlo Zancanaro

carlo.zancanaro@univr.it

Specialty section:

This article was submitted to

Exercise Physiology,

a section of the journal

Frontiers in Physiology

Received: 21 October 2020 Accepted: 07 December 2020 Published: 23 December 2020

Citation:

Cavedon V, Sandri M,

Venturelli $M$, Zancanaro $C$ and Milanese C (2020) Anthropometric

Prediction of DXA-Measured Percentage of Fat Mass in Athletes

With Unilateral Lower Limb

Amputation.

Front. Physiol. 11:620040. doi: 10.3389/fphys.2020.620040

\section{Anthropometric Prediction of DXA-Measured Percentage of Fat Mass in Athletes With Unilateral Lower Limb Amputation}

\author{
Valentina Cavedon, Marco Sandri, Massimo Venturelli, Carlo Zancanaro* and \\ Chiara Milanese
}

Department of Neurosciences, Biomedicine and Movement Sciences, University of Verona, Verona, Italy

To date there is no anthropometric equation specific to athletes with unilateral lower limb amputation to estimate the percentage of fat mass (\%FM). This study investigated the accuracy of a set of anthropometric equations validated on able-bodied populations to predict the \%FM assessed by-means of dual-energy $\mathrm{x}$-ray absorptiometry (DXA) in athletes with unilateral lower limb amputation. Furthermore, a predictive anthropometric equation specific to athletes with unilateral lower limb amputation was developed from skinfold thickness measurements using DXA as the reference method for the estimation of the \%FM. Twenty-nine white male athletes with unilateral lower limb amputation underwent a DXA scan and an anthropometric assessment on the same day. The $\% F M$, calculated through several existing anthropometric equations validated upon able-bodied populations, was compared with the DXA-measured \%FM (\%FM_DXA). Accuracy and agreement between the two methods was computed with two-tailed paired-sample $t$-test, concordance correlation coefficient, reduced major axis regression and Bland-Altman analysis. A stepwise multiple regression analysis with the \%FM_DXA as the dependent variable and age and nine skinfold thicknesses as potential predictors was carried out and validated using a repeated 10-fold cross-validation. A linear regression analysis with the sum of nine skinfolds as the independent variable was also carried out and validated using a repeated 10-fold cross-validation. The results showed that the anthropometric equations validated on able-bodied populations are inaccurate in the estimation of \%FM_DXA with an average bias ranging from 0.51 to $-13.70 \%$. Proportional bias was also found revealing that most of the anthropometric equations considered, tended to underestimate/overestimate the \%FM_DXA as body fat increased. Regression analysis produced two statistically significant models $(P<0.001$ for both) which were able to predict more than 93\% of total variance of \%FM_DXA from the values of four skinfold measurements (i.e., thigh, abdominal, subscapular and axillary skinfold measurements) or from the sum of 9 skinfolds. Repeated cross-validation 
analysis highlighted a good predictive performance of the proposed equations. The predictive equations proposed in this study represent a useful tool for clinicians, nutritionists, and physical conditioners to evaluate the physical and nutritional status of athletes with unilateral lower limb amputation directly in the field.

Keywords: body composition, skinfold thickness, athletes with physical impairments, predictive equation, blandaltman analysis

\section{INTRODUCTION}

Amputation is defined as the total or partial absence of bones and/or joints as a result of trauma, illness (e.g., bone cancer or diabetes) or congenital anomalies (Simim et al., 2013). Among the various types of physical impairments, amputation on a lower limb has been shown to have a high prevalence worldwide (Wasser et al., 2020). Today, people suffering from unilateral lower limb amputation are eligible to participate in a wide range of adapted sports, such as amputee soccer, wheelchair basketball, wheelchair tennis, track and field, para swimming, handbike and so on (World Amputee Football Federation, 2005; International Paralympic Committee, 2019). In recent years, participation in such adapted sports is constantly growing around the world (Ozkan et al., 2012; Simim et al., 2013; International Paralympic Committee, 2017, 2019).

After a lower-limb amputation, subjects undergo changes in their body composition including increased whole-body adiposity (Sherk et al., 2010) along with muscle atrophy and an increase in the amount of fat mass in the residual limb (Sherk et al., 2010). Such changes in body composition are associated with negative consequences from both a health (Anderson et al., 2013) and a performance perspective (Ozkan et al., 2012). Accordingly, an accurate assessment of body composition in athletes with unilateral lower limb amputation is of great importance in view of assessing their nutritional and training status, as well as monitoring the impact of dietary and training interventions.

Today, the Dual-Energy X-Ray Absorptiometry (DXA) is recognized as an accurate method to objectively assess body composition in athletes with a physical impairment (Keil et al., 2014). However, DXA may not be readily available in many clinical and sport settings due to logistics and costs. As an alternative, in sport practice as well as in several scientific studies (Iturricastillo et al., 2015; Cavedon et al., 2018a, 2015), anthropometry is often employed as a cost-effective and accessible method to assess body composition directly in the field.

The accuracy of anthropometry lies in the use of predictive equations which are specific to the population under evaluation (Heyward and Wagner, 2004; Reilly et al., 2009). In fact, predictive equations are based on the assumption that within each population body fat is distributed subcutaneously and internally in a similar manner in all individuals (Heyward and Wagner, 2004). Body fat distribution is influenced by several factors and varies for example across age groups, gender, ethnicity, and, in the case of athletes, also the particular sport practiced (Reilly et al., 2009; Cavedon et al., 2018b). Furthermore, in athletes with a physical impairment, some studies (Willems et al., 2015; Goosey-Tolfrey et al., 2016; Flueck, 2020) has underlined that the distribution of fat mass is also influenced by the type of physical impairment (e.g., spinal cord injury or lower limb amputations), and the associated modality of daily ambulation (i.e., wheelchair, prosthesis or crutches).

Many predictive anthropometric equations are nowadays available for different populations of able-bodied subjects, both non-athletes (Katch and McArdle, 1973; Durnin and Womersley, 1974; Pollock et al., 1976; Ball et al., 2004; Eston et al., 2005; O'Connor et al., 2010; Bacchi et al., 2017) and athletes (White et al., 1980; Thorland et al., 1984; Evans et al., 2005; Reilly et al., 2009; Oliver et al., 2012; Cavedon et al., 2018b).

To the best of our knowledge, no anthropometric equation specific to athletes with unilateral lower limb amputation has been developed yet. Moreover, the capability of the anthropometric equations developed in able-bodied populations in predicting the DXA-measured whole-body percentage of fat mass $\left(\% \mathrm{FM}_{\mathrm{DXA}}\right)$ has never been investigated in athletes with unilateral lower limb amputation. Some studies showed a lack of transferability of the anthropometric equations developed for able-bodied populations (Wilmore and Behnke, 1970; Durnin and Womersley, 1974) to athletes with a physical impairment (e.g., athletes with spinal cord injury or mixed groups of athletes with different types of physical impairments) (Sutton et al., 2009; Willems et al., 2015; Goosey-Tolfrey et al., 2016). Taken together, these studies (Goosey-Tolfrey et al., 2016; Sutton et al., 2009; Willems et al., 2015) revealed that such anthropometric equations systematically underestimate the $\% \mathrm{FM}_{\mathrm{DXA}}$ in athletes with a physical impairment.

The aim of the present study was to investigate the ability of a set of anthropometric equations validated in ablebodied athletic and non-athletic populations to estimate the $\% \mathrm{FM}_{\mathrm{DXA}}$ in athletes with unilateral lower limb amputation. Furthermore, population-specific predictive equations for \%FM were developed from skinfold thickness measurements using DXA as the reference method.

\section{MATERIALS AND METHODS}

\section{Participants}

The required sample was estimated "a priori" using G*Power ver.3.1.9.2 (Faul, 2009). Setting the type I error at $\alpha=0.05$ and the effect size at $d=0.60$, the minimum sample size required for the two-tailed paired-sample $t$-test to reach an $80 \%$ power (i.e., $\beta=0.20$ ) was 24 subjects. In order to comply with a possible $\sim 20 \%$ dropout, thirty participants were initially 
recruited. Inclusion criteria were practicing an adapted sport at a competitive level for more than 1 year prior to testing and not suffering from any chronic or systemic disease or other physical impairments, apart from the amputation, that might affect body composition. One athlete did not complete the measurements therefore twenty-nine male white athletes with unilateral lower limb amputation were considered for the analysis. These athletes suffered from amputation through the hip or transfemoral amputation $(n=14)$, amputation through the knee or transtibial amputation $(n=13)$, amelia of a lower limb $(n=1)$, leg length discrepancy $(n=1)$. The mean age of the athletes was $35.86 \pm 9.11$ years. The cause of amputation was traumatic in 27 athletes and congenital in 2 athletes. In the case of amputation due to a trauma, the duration of injury was $13.8 \pm 1.9$ years. Athletes had been regularly involved in amputee soccer $(n=11)$, sitting volley $(n=1)$, wheelchair basketball $(n=4)$, track and field $(n=4)$, paratriathlon $(n=2)$, para ice hockey $(n=1)$, skydiving $(n=1)$, and handbike $(n=5)$ for $7.5 \pm 1.2$ years. All athletes competed at national level and 15 of them competed also at international level. The weekly amount of training was $5.0 \pm 0.4$.

When assessing the possible impact of the level of amputation on the $\% \mathrm{FM}_{\mathrm{DXA}}$ and the DXA-measured regional \%FM, athletes were divided into two groups: athletes with above-knee amputation (AKA, $n=16$, including athletes with transfemoral lower limb amputation and athletes with amelia) and athletes with below-knee amputation (BKA, $n=14$, including athletes with transtibial lower limb amputation and athletes with leg length discrepancy).

The study was conducted in accordance with the Declaration of Helsinki, and the protocol was approved by the Institutional Review Board of the local University. All the participants were informed about the aims of the study and the experimental procedures, and they knew that they could withdraw at any time. All participants read and signed the informed consent form.

\section{Procedures}

On the same day, athletes underwent an anthropometric evaluation and a whole-body DXA scan. The measurement session took place in the morning, after a 3-4 h fast. During all measurements the participants wore minimal clothing (i.e., underwear). All participants were asked not to undertake any strenuous physical activity the day before each measurement session and they were also required not to undertake any exercise on the morning of the measurements.

The participants were asked to wear their prosthesis before having their body weight and stature measured. Body mass was assessed with prosthesis to the nearest $0.1 \mathrm{~kg}$ using a certified electronic scale (Tanita electronic scale BWB-800 MA, Wunder SA.BI. Srl, Milan, Italy). The weight of the prosthesis was then taken and subtracted from the previous weight with the prosthesis to get the actual body mass. Standing height was measured to the nearest $0.1 \mathrm{~cm}$ using a Harpenden portable stadiometer (Holtain Ltd., Crymych, Pembs. United Kingdom) according to conventional criteria and measuring procedures (Lohman et al., 1988).
Body composition was assessed by means of Dual-Energy X-ray Absorptiometry (DXA) on a QDR Explorer fan beam densitometer (Hologic, MA, United States). In our laboratory quality control of the DXA scanner is performed daily before actual use by means of an encapsulated spine phantom (Hologic Inc., Bedford, MA, United States) to check for possible baseline drift. Participants undertook whole-body DXA scanning according to "The Best Practice Protocol for the assessment of whole-body body composition by DXA" (Nana et al., 2015). Positioning aids to support the residual lower limb were employed and special strapping was applied around participants' residual ankle to ensure there was no movement during the scans. Prior to scanning, participants were asked to void their bladder and to remove all metal, jewelry or reflective material, including prostheses.

Analysis of DXA scans was performed using Hologic Discovery software for Windows XP version 12.6.1 according to the manufacturer's procedures to get the $\% \mathrm{FM}_{\mathrm{DXA}}$ and the percentage of fat mass (\%FM) in the trunk, arms (right and left) and legs (right and left) regions. For analysis at the regional level, the average \% FM of the right and the left arm (arms) and the \%FM of the non-impaired leg were used. The same trained investigator carried out all measurements and analyzed all the DXA scans to ensure consistency.

Skinfold thicknesses were measured to the nearest $0.2 \mathrm{~mm}$ by the same trained investigator with a Harpenden caliper (Gima, Milan, Italy) at the biceps, triceps, subscapular, chest, axilla, suprailiac, abdominal, anterior thigh (of the non-impaired leg) and calf (of the non-impaired leg) according to standard procedures (Lohman et al., 1988). Duplicate readings were taken at each site, and the average of the two was recorded.

Body density or the \%FM were calculated using nine anthropometric equations developed in able-bodied athletic populations (Forsyth and Sinning, 1973; White et al., 1980; Thorland et al., 1984; Evans et al., 2005; Reilly et al., 2009; Oliver et al., 2012) and nine anthropometric equations developed in able-bodied non-athletic populations (Nagamine and Suzuki, 1964; Sloan, 1967; Wilmore and Behnke, 1970; Katch and McArdle, 1973; Durnin and Womersley, 1974; Pollock et al., 1976; Ball et al., 2004; Eston et al., 2005; O'Connor et al., 2010; Table 1). Body density values were converted to \%FM according to Siri (1961).

\section{Statistical Analysis}

The normality of data was checked, and all variables did not show significant deviations from the gaussian distribution. Descriptive statistics (mean and standard deviation) were computed for all variables.

Differences in the \%FM $\mathrm{FXX}_{\mathrm{DX}}$ and the DXA-measured regional \%FM between the AKA e BKA groups were assessed by the twotailed independent-sample $t$ test. As the AKA and BKA groups were similar in both the $\% \mathrm{FM}_{\mathrm{DXA}}$ and the regional $\% \mathrm{FM}$, the level of amputation was not taken into account for further analyses and the study sample was considered as a whole.

Mean bias (i.e., the average of the differences between the \%FM obtained by each anthropometric equation and the $\left.\% \mathrm{FM}_{\mathrm{DXA}}\right)$ was computed to get a measure of systematic 
TABLE 1 | Anthropometric equations used to predict the body density or the percentage of body fat in athletes with unilateral lower limb amputation.

\begin{tabular}{|c|c|c|}
\hline References & Abbreviation & Anthropometric equation \\
\hline Forsyth and Sinning, 1973 & Eq_Fs2 & $\mathrm{BD}=1.1103-(0.00168 \cdot \mathrm{SS})-(0.00127 \cdot \mathrm{AB})$ \\
\hline Forsyth and Sinning, 1973 & Eq_Fs4 & $\mathrm{BD}=1.10647-(0.00162 \cdot \mathrm{SS})-(0.00144 \cdot \mathrm{AB})-(0.00077 \cdot \mathrm{TR})+(0.00071 \cdot \mathrm{AX})$ \\
\hline Thorland et al., 1984 & Eq_Th3 & $\mathrm{BD}=1.1136-[0.00154 \cdot(\mathrm{TR}+\mathrm{SS}+\mathrm{AX})]+\left[0.00000516 \cdot(\mathrm{TR}+\mathrm{SS}+\mathrm{AX})^{2}\right]$ \\
\hline Thorland et al., 1984 & Eq_Th7 & $\begin{array}{l}B D=1.1091-[0.00052 \cdot(T R+S S+A X+S I+A B+T H+C A)]++[0.00000032 \\
\left.(T R+S S+A X+S I+A B+T H+C A)^{2}\right]\end{array}$ \\
\hline White et al., 1980 & Eq_Whi & $\mathrm{BD}=1.0958-(0.00088 \cdot \mathrm{SI})-(0.0006 \cdot \mathrm{TH})$ \\
\hline Evans et al., 2005 & Eq_Ev3 & $\% \mathrm{FM}=8.997+[0.24658 \cdot(\mathrm{TR}+\mathrm{SI}+\mathrm{TH})]-(6.343 \cdot \mathrm{Sex})-(1.998 \cdot$ Race $)$ \\
\hline Evans et al., 2005 & Eq_Ev7 & $\begin{array}{l}\% F M=10.566+[0.12077 \cdot(T R+S I+T H+S S+A X+C H+A B)]-(8.057 \cdot S e x)-(2.545 \cdot \\
\text { Race) }\end{array}$ \\
\hline Oliver et al., 2012 & Eq_Oli & $\% F M=3.53+[0.132 \cdot(T R+S I+T H+S S+A X+C H+A B)]$ \\
\hline Reilly et al., 2009 & Eq_Rei & $\% \mathrm{FM}=5.174+(0.124 \cdot \mathrm{CH})+(0.147 \cdot \mathrm{AB})+(0.196 \cdot \mathrm{TR})+(0.13 \cdot \mathrm{CA})$ \\
\hline Durnin and Womersley, 1974 & Eq_DWg & $\mathrm{BD}=1.1765-\left[0.0744 \cdot \log _{10}(\mathrm{BI}+\mathrm{TR}+\mathrm{SS}+\mathrm{SI})\right]$ \\
\hline Katch and McArdle, 1973 & Eq_KMc & $\mathrm{BD}=1.09665-(0.00103 \cdot \mathrm{TR})-(0.00056 \cdot \mathrm{SS})-(0.00054 \cdot \mathrm{AB})$ \\
\hline Nagamine and Suzuki, 1964 & Eq_NaS & $\mathrm{BD}=1.0913-[0.00116 \cdot(\mathrm{TR}+\mathrm{SS})]$ \\
\hline Pollock et al., 1976 & Eq_Pol & $\mathrm{BD}=1.09716-(0.00065 \cdot \mathrm{CH})-(0.00055 \cdot \mathrm{SS})-(0.0008 \cdot \mathrm{TH})$ \\
\hline Sloan, 1967 & Eq_Slo & $\mathrm{BD}=1.1043-(0.001327 \cdot \mathrm{TH})-(0.00131 \cdot \mathrm{SS})$ \\
\hline Wilmore and Behnke, 1970 & Eq_WiB & $\mathrm{BD}=1.08543-(0.000886 \cdot \mathrm{AB})-(0.0004 \cdot \mathrm{TH})$ \\
\hline Ball et al., 2004 & Eq_Bal & $\begin{array}{l}\% F M=0.465+[0.18 \cdot(\mathrm{CH}+\mathrm{AX}+\mathrm{TR}+\mathrm{SS}+\mathrm{AB}+\mathrm{SI}+\mathrm{TH})]--[0.0002406 \\
\left.(\mathrm{CH}+\mathrm{AX}+\mathrm{TR}+\mathrm{SS}+\mathrm{AB}+\mathrm{SI}+\mathrm{TH})^{2}\right]+(0.06619 \cdot \text { age })\end{array}$ \\
\hline Eston et al., 2005 & Eq_Est & $\% \mathrm{FM}=[0.12 \cdot(\mathrm{BI}+\mathrm{TR}+\mathrm{SS}+\mathrm{SI})]+[0.36 \cdot(\mathrm{TH}+\mathrm{CA})]+1.61$ \\
\hline O'Connor et al., 2010 & Eq_Oco & $\% \mathrm{FM}=[0.272 \cdot(\mathrm{TR}+\mathrm{SI}+\mathrm{TH})]-[0.0005 \cdot(\mathrm{TR}+\mathrm{SI}+\mathrm{TH})]+4.972$ \\
\hline
\end{tabular}

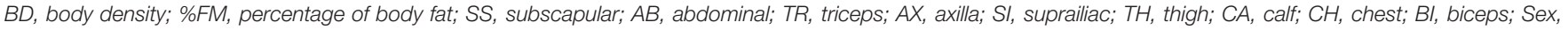
male = 1 and female =0; Race, black $=1$ and white $=0$.

measurement errors. The \%FM obtained by each anthropometric equation was compared with the \%FM DXA $_{\text {using the two- }}$ tailed paired-sample $t$-test. The Lin's concordance correlation coefficient $(\rho c)$ was used to quantify the agreement between the $\% \mathrm{FM}_{\mathrm{DXA}}$ and each anthropometric equation (Lin, 1989); agreement was considered poor $(\rho c<0.90)$, moderate $(\rho c$ between 0.90 and 0.95 ), substantial ( $\rho c$ between 0.95 and 0.99 ), excellent $(\rho c>0.99)$ and perfect $(\rho c=1)$. The intraclass correlation coefficient ( $r$ ) was also calculated as a measure of validity according to Fisher (Fisher, 1950; page 212) and interpreted according to Cicchetti (1994) as poor $(r<0.40)$, fair ( $\mathrm{r}$ between 0.40 and 0.59 ), good ( $\mathrm{r}$ between 0.60 and 0.74 ) and excellent ( $\mathrm{r}$ between 0.75 and 1.00). The Reduced Major Axis (RMA) regression (Harper, 2014) was used to assess the relationship between the $\% \mathrm{FM}_{\mathrm{DXA}}$ (i.e., the dependent variable) and the $\% \mathrm{FM}$ predicted by each anthropometric equation. In case of perfect agreement, the intercept and the slope of the RMA line are 0 and 1 , respectively.

Agreement between each anthropometric equation and DXA was tested using Bland-Altman analysis (limits of agreement and range) (Bland and Altman, 2012). The presence of proportional bias was explored by examining the association between the mean bias and the average of the two methods (i.e., the average between the \%FM obtained with each anthropometric equation and the $\% \mathrm{FM}_{\mathrm{DXA}}$ ) by the Pearson's product-moment correlation coefficient $(\mathrm{r})$. The strength of the correlation coefficient was considered small $(r=0.00-0.30)$, moderate $(r=0.31-0.49)$, large $(r=0.50-0.69)$, very large $(r=0.70-0.89)$, and almost perfect for assessing relationships $(r=0.90-1.00)$ as suggested by Hopkins (2016).
A stepwise multiple regression analysis was carried out with the $\% \mathrm{FM}_{\mathrm{DXA}}$ as the dependent variable and with age and 9 skinfold thicknesses (i.e., biceps, triceps, subscapular, axilla, chest, suprailiac, abdominal, anterior thigh, and calf skinfolds) as potential predictors. The value of probability of F-to-enter was equal to 0.05 and the probability of F-to-remove was equal to 0.10 . The adjusted coefficient of determination $\left(\mathrm{R}^{2}\right)$ and the standard error of estimate (SEE) were used to represent the goodness-of-fit of the predictor model. Homoscedasticity of data was assessed by plotting the residuals of multiple regression analysis against the predicted values. The DurbinWatson test was used to test for autocorrelation in the residuals, while the variance inflation factor and the condition index were calculated to test collinearity. A linear regression analysis with the $\% \mathrm{FM}_{\mathrm{DXA}}$ as the dependent variable and the sum of 9 skinfolds as the independent variable was also carried out. For both the regression models, Cohen's $f$ squared $\left(f^{2}\right)$ was used to calculate the effect size of the regression model and interpreted as small $\left(f^{2} \geq 0.02\right)$, medium $\left(f^{2} \geq 0.15\right)$ and large $\left(f^{2} \geq 0.35\right)$ according to Cohen's guidelines (Cohen, 1988). The developed regression models were then validated using a repeated 10-fold cross-validation (with 1000 replications), estimating for each cross-validation sample the root mean squared prediction error (RMSPE), the coefficient of determination $\mathrm{R}^{2}$, and the mean absolute prediction error (MAPE).

Statistical analyses were performed using SPSS v. 16.0 (IBM Corp., Armonk, NY, United States) and R-4.0.3 (Foundation for Statistical Computing, Vienna). The statistical significance was set at $P \leq 0.05$. 


\section{RESULTS}

Descriptive statistics (mean and standard deviation) for age, ${ } \mathrm{FM}_{\mathrm{DXA}}$ and the DXA-measured regional \%FM of the whole sample as well as for the AKA and BKA groups are reported in Table 2. The $t$-test showed no statistically significant differences between the AKA and BKA groups in age, \%FM $\mathrm{DXA}_{\mathrm{A}}$ and the DXA-measured regional \%FM (Table 2).

A summary of the results related to accuracy and agreement in the estimate of the \%FM by each anthropometric equation versus the $\% \mathrm{FM}_{\mathrm{DXA}}$ is presented in Table 3. The $t$-test showed that only the average \%FM obtained with the Eq_DWg (Durnin and Womersley, 1974) was similar to the average \%FM $\mathrm{DXA}_{\text {, }}$ while all other anthropometric equations were significantly different to the $\% \mathrm{FM}_{\mathrm{DXA}}$. The limits of agreement showed that 95\% of the time, the Eq_DWg (Durnin and Womersley, 1974) produced \%FM estimates that were between $-3.8 \%$ less and $4.9 \%$ higher than the $\% \mathrm{FM}_{\mathrm{DXA}}$. The two-tailed pairedsample $t$-test also revealed that the Eq_Fs4 (Forsyth and Sinning, 1973) significantly overestimated the \%FM when compared with the $\% \mathrm{FM}_{\mathrm{DXA}}$, with a systematic bias equal to $1.31 \%$. In this anthropometric equation, the $95 \%$ limits of agreement of the bias ranged from $-2.5 \%$ less and to $5.1 \%$ more. All other anthropometric equations significantly underestimated the $\% \mathrm{FM}$ versus $\% \mathrm{FM}_{\mathrm{DXA}}$ (Table 3 ), with systematic bias ranging from $-1.14 \%$ (Eq_Bal) to $-8.03 \%$ (Eq_Whi). The $\rho c$ showed poor agreement between the $\% \mathrm{FM}$ obtained with each of the considered anthropometric equations and the $\% \mathrm{FM}_{\mathrm{DXA}}$ $(\rho c<0.90$ for all, Table 3). According to Cicchetti (1994), the intraclass correlation coefficient $\mathrm{r}$ was considered poor (Eq_Whi,

TABLE 2 | Participant's age and DXA-measured whole-body and regional percentage of fat mass.

\begin{tabular}{|c|c|c|c|c|c|c|c|c|}
\hline \multirow[b]{2}{*}{ Variables } & \multicolumn{2}{|c|}{ Whole sample $(n=29)$} & \multicolumn{2}{|c|}{ AKA $(n=15)$} & \multicolumn{2}{|c|}{ BKA $(n=14)$} & \multicolumn{2}{|c|}{ Independent-sample $t$-test } \\
\hline & Mean & SD & Mean & SD & Mean & SD & $t$ & $P$ \\
\hline Age (years) & 35.86 & 9.11 & 35.22 & 12.91 & 37.08 & 13.48 & 0.440 & 0.664 \\
\hline$\% F M_{D X A}$ & 21.67 & 4.40 & 21.80 & 4.05 & 22.20 & 4.23 & 0.147 & 0.884 \\
\hline Trunk\%FM & 21.16 & 5.39 & 21.04 & 5.33 & 22.11 & 5.56 & 0.608 & 0.549 \\
\hline Arms\%FM & 19.42 & 4.51 & 19.16 & 4.82 & 20.28 & 5.03 & 0.417 & 0.680 \\
\hline N-I leg\%FM & 22.44 & 4.80 & 22.98 & 4.99 & 22.50 & 5.21 & -0.318 & 0.753 \\
\hline
\end{tabular}

AKA, above-knee amputee athletes; BKA, below-knee amputee athletes; SD, standard deviation; \%FMDXA, DXA-measured whole-body percentage of fat mass; \%FM, percentage of fat mass; N-I, non-impaired.

TABLE 3 | Analysis of the agreement between the percentage of fat mass obtained with anthropometric equations and the percentage of fat mass obtained by-means of DXA.

\begin{tabular}{|c|c|c|c|c|c|c|c|c|c|c|c|c|c|}
\hline \multirow[b]{2}{*}{$\mathrm{AE}$} & \multicolumn{2}{|c|}{ Descriptive statistics } & \multicolumn{3}{|c|}{ Paired $t$-test } & \multirow{2}{*}{$\begin{array}{c}\text { CCC } \\
\rho c\end{array}$} & \multirow{2}{*}{$\frac{\text { ICC }}{r}$} & \multicolumn{2}{|c|}{ RMA regression } & \multicolumn{4}{|c|}{ Bland-Altman analysis } \\
\hline & Mean & SD & Bias & $\mathbf{t}$ & $\mathbf{P}$ & & & Slope & Int & U LoA & L LoA & Range & $\mathbf{r}$ \\
\hline Eq_Fs2 & 20.16 & 4.15 & -1.51 & 5.45 & $<0.001$ & 0.88 & 0.88 & 0.94 & -0.23 & 1.42 & -4.45 & 5.86 & -0.18 \\
\hline Eq_Fs4 & 22.98 & 4.28 & 1.31 & -3.69 & 0.001 & 0.86 & 0.86 & 0.97 & 1.95 & 5.06 & -2.45 & 7.50 & -0.07 \\
\hline Eq_Th3 & 17.73 & 4.01 & -3.94 & 11.00 & $<0.001$ & 0.62 & 0.55 & 0.91 & -1.96 & -0.16 & -7.72 & 7.56 & -0.21 \\
\hline Eq_Th7 & 19.91 & 4.48 & -1.76 & 7.214 & $<0.001$ & 0.88 & 0.88 & 1.02 & -2.08 & 0.82 & -4.34 & 5.16 & 0.05 \\
\hline Eq_Whi & 13.64 & 3.20 & -8.03 & 20.70 & $<0.001$ & 0.26 & 0.13 & 0.73 & -2.08 & -3.93 & -12.12 & 8.19 & -0.59 \\
\hline Eq_Ev3 & 14.94 & 2.91 & -6.73 & 17.53 & $<0.001$ & 0.32 & 0.00 & 0.66 & 0.63 & -2.66 & -10.80 & 8.13 & -0.74 \\
\hline Eq_Ev7 & 16.68 & 2.83 & -4.98 & 14.94 & $<0.001$ & 0.46 & 0.28 & 0.64 & 2.76 & -1.45 & -8.53 & 7.08 & -0.88 \\
\hline Eq_Oli & 19.02 & 3.10 & -2.64 & 8.93 & $<0.001$ & 0.73 & 0.70 & 0.70 & 3.81 & 0.49 & -5.79 & 6.28 & -0.83 \\
\hline Eq_Rei & 14.25 & 1.52 & -7.42 & 13.33 & $<0.001$ & 0.16 & 0.31 & 0.35 & 6.76 & -1.53 & -13.31 & 11.78 & -0.97 \\
\hline Eq_DWg & 22.18 & 3.25 & 0.51 & -1.25 & 0.221 & 0.83 & 0.83 & 0.74 & 6.22 & 4.86 & -3.84 & 8.71 & -0.54 \\
\hline Eq_KMc & 15.96 & 2.48 & -5.70 & 13.32 & $<0.001$ & 0.34 & 0.08 & 0.56 & 3.77 & -1.17 & -10.24 & 9.07 & -0.85 \\
\hline Eq_NaS & 17.51 & 2.70 & -4.16 & 8.47 & $<0.001$ & 0.44 & 0.30 & 0.61 & 4.26 & 1.03 & -9.35 & 10.39 & -0.68 \\
\hline Eq_Pol & 14.88 & 3.29 & -6.78 & 19.29 & $<0.001$ & 0.34 & 0.05 & 0.75 & -1.27 & -3.06 & -10.51 & 7.46 & -0.60 \\
\hline Eq_Slo & 17.51 & 4.75 & -4.16 & 9.60 & $<0.001$ & 0.61 & 0.54 & 1.08 & -5.85 & 0.41 & -8.74 & 9.16 & 0.15 \\
\hline Eq_WiB & 18.43 & 2.42 & -3.24 & 7.31 & $<0.001$ & 0.54 & 0.46 & 0.55 & 6.53 & 1.45 & -7.94 & 9.39 & -0.85 \\
\hline Eq_Bal & 20.52 & 3.29 & -1.14 & 3.61 & 0.001 & 0.86 & 0.86 & 0.75 & 4.36 & 2.22 & -4.51 & 6.73 & -0.66 \\
\hline Eq_Est & 18.90 & 3.86 & -2.77 & 7.09 & $<0.001$ & 0.71 & 0.68 & 0.88 & -0.07 & 1.36 & -6.90 & 8.25 & -0.27 \\
\hline Eq_Oco & 18.50 & 3.21 & -3.17 & 8.88 & $<0.001$ & 0.65 & 0.60 & 0.73 & 2.75 & 0.61 & -6.95 & 7.56 & -0.64 \\
\hline
\end{tabular}

CCC, concordance correlation coefficient; ICC, intraclass correlation coefficient r; RMA, reduced major axis; AE, anthropometric equations; SE, standard error; P, P-value; $U$, upper; L, lower; LoA, limits of agreement; r, Pearson's correlation coefficient indicating the association between the difference and the mean between the two methods; $\rho c$, Lin's concordance correlation coefficient; Int, intercept. 
Eq_Ev3; Eq_Ev7; Eq_Rei; Eq_KMc; Eq_NaS; Eq_Pol), fair (Eq_Th3, Eq_Slo; Eq_WiB), good (Eq_Oli, Eq_Est, Eq_Oco) or excellent (Eq_Fs2, Eq_Fs4, Eq_Th7, Eq_DWg, Eq_Bal). The slope and the intercept of the RMA were, respectively, near to 1 and to 0 for the $\% \mathrm{FM}_{\mathrm{DXA}}$ and the Eq_Fs2 as well as for the $\% \mathrm{FM}_{\mathrm{DXA}}$ and the Eq_Est indicating good concordance between these measurements. All other measurements showed poor agreement.

The agreement between the \%FM obtained by a set of anthropometric equations and the $\% \mathrm{FM}_{\mathrm{DXA}}$ is depicted in Figures 1, 2. Despite at least $93 \%$ of the data points falling within the $95 \%$ limits of agreement in each Bland-Altman plot (Figures 1, 2), the range of the limits of agreement in each plot was large (i.e., higher than 5.16; Table 3), indicating poor agreement.

The correlation analysis showed that the association between the difference and the mean values of the two methods used to estimate the \%FM (i.e., each anthropometric equation and DXA) was small (Eq_Fs2 vs. DXA; Eq_Fs4 vs. DXA; Eq_Th3 vs. DXA, Eq_ Th7 vs. DXA, Eq_Slo vs. DXA, Eq_Est vs. DXA), large (Eq_Whi vs. DXA, Eq_DWg vs. DXA, Eq_Nas vs. DXA, Eq_Pol vs. DXA, Eq_Bal vs. DXA, Eq_Oco vs. DXA), very large (Eq_Ev3 vs. DXA, Eq_Ev7 vs. DXA, Eq_Oli vs. DXA, Eq_KMc vs. DXA, Eq_WiB vs. DXA) and almost perfect (Eq_Rei vs. DXA), indicating that as the $\% \mathrm{FM}_{\mathrm{DXA}}$ increased, so did the underestimation/overestimation of the \%FM with most of the considered anthropometric equations (Table 3 and Figures 1, 2).

In the whole sample, by entering age and nine skinfold thicknesses (i.e., biceps, triceps, subscapular, axilla, chest, suprailiac, abdominal, anterior thigh, and calf skinfolds) as potential predictors in stepwise multiple regression analysis, a statistically significant model was estimated for $\% \mathrm{FM}_{\mathrm{DXA}}$ $(F=116.272, P<0.001)$. The model was:

\section{$\% \mathrm{FM}_{\mathrm{DXA}}=\mathbf{0 . 2 4 1}($ Anterior Thigh Skinfold $)+\mathbf{0 . 4 1 8}$}

\section{(Abdominal Skinfold $)+0.329$ (Subscapular Skinfold $)$}

$$
\text { + 0.259 (Axillary Skinfold) - 1.689. }
$$

Adjusted $\mathrm{R}^{2}$, SEE and $f^{2}$ were $0.943,1.05$ and 16.54 , respectively. The Durbin-Watson was 2.30, indicating that there was no autocorrelation between the residuals. The variance inflation factor and the condition index were, respectively, $<2.6$ and $<24.9$ for all the predicting variables showing that multicollinearity between the variables in the model was weak.

The validation of our model using a repeated 10-fold cross-validation, showed that the model has good predictive performance (mean RMSPE $=1.51$ [range $=1.06-2.18$ ]; mean $R^{2}=0.89$ [range $\left.=0.78-0.94\right]$; mean $\mathrm{MAPE}=1.18$ [range $=0.85-1.73]$ ).

As several of the existing anthropometric equations used the sum of skinfolds as a predictor of the body density or the \%FM, we also calculated the prediction of a regression model using the sum of 9 skinfolds as the independent variable. Analysis yielded a statistically significant model $(F=357.63, P<0.001)$ with a good predictivity $\left(R^{2}=0.93\right)$. The model was:

$$
\% \mathrm{FM}_{\mathrm{DXA}}=0.162(\text { Sum of Nine Skinfolds })-0.311
$$

SEE and $f^{2}$ were 1.19 and 13.08 , respectively.

The validation of our model using a repeated 10-fold cross-validation, showed that the model has good predictive performance (mean RMSPE $=1.23$ [range $=1.15-1.39$ ]; mean $R^{2}=0.92$ [range $=0.90-0.93$ ]; mean $\mathrm{MAPE}=1.03$ [range $=0.96-$ $1.18])$.

Bland-Altman plots of the developed equations have been provided as Supplementary Material.

\section{DISCUSSION}

Evaluating and monitoring body composition is a key issue in adapted sports practice due to its link to both health and performance. The accurate assessment of body composition in athletes with a physical impairment is a difficult task due to the different types of physical impairment (e.g., spinal cord injury or limb amputation/s) and the consequent differences in the distribution of body fat in comparison with able-bodied persons (Willems et al., 2015). To the best of our knowledge, there is no scientific data related to the capability of field measurements (e.g., skinfold thickness) in accurately assessing body composition in athletes with unilateral lower limb amputation. In order to fill this gap in the scientific literature, this study aimed to assess the ability of a set of anthropometric equations validated upon athletic and non-athletic able-bodied populations in estimating the $\% \mathrm{FM}$ in athletes with unilateral lower limb amputation, using the $\% \mathrm{FM}_{\mathrm{DXA}}$ as the criterion. Furthermore, this study is the first attempt to develop anthropometric equations specific for this athletic population to predict the $\% \mathrm{FM}_{\mathrm{DXA}}$.

A primary finding of the present study was that almost all of the anthropometric equations obtained from both athletic and non-athletic able-bodied populations are inaccurate in estimating the \%FM amputation. The \%FM obtained by the Eq_DWg was the only anthropometric equation able to predict the \%FM close to the $\% \mathrm{FM}_{\mathrm{DXA}}$ with a mean bias equal to $0.51 \%$, the difference being not statistically significant (Table 3). However, the Bland-Altman plot (Figure 2) showed that, even if all points fell within the $95 \%$ limits of agreement, the range of the limits of agreement was wide (i.e., $8.71 \%$ ) making the prediction inaccurate. For all the other anthropometric equations under investigation, the two-tailed paired-sample $t$-test revealed a statistically significant, systematic bias leading to underestimation or overestimation of $\% \mathrm{FM}_{\mathrm{DXA}}$ in athletes with unilateral lower limb amputation (Table 3). More specifically, of the nine anthropometric equations validated in athletic able-bodied populations, only one equation (i.e., Eq_Sf4) overestimated the \%FM $\mathrm{DXX}_{\mathrm{DA}}$, while the other eight equations underestimated the \%FM $\mathrm{DXX}_{\mathrm{A}}$. Instead, all anthropometric equations validated in non-athletic able-bodied populations (except Eq_DWg) systematically underestimated the $\% \mathrm{FM}_{\mathrm{DXA}}$. Moreover, a large $(> \pm 4 \%)$ systematic bias was found in 8 out of 18 of the evaluated anthropometric equations ( 4 validated upon athletes and 4 validated upon nonathletes) (Table 3).

These results are partially in line with data from others (Willems et al., 2015) reporting that four anthropometric 


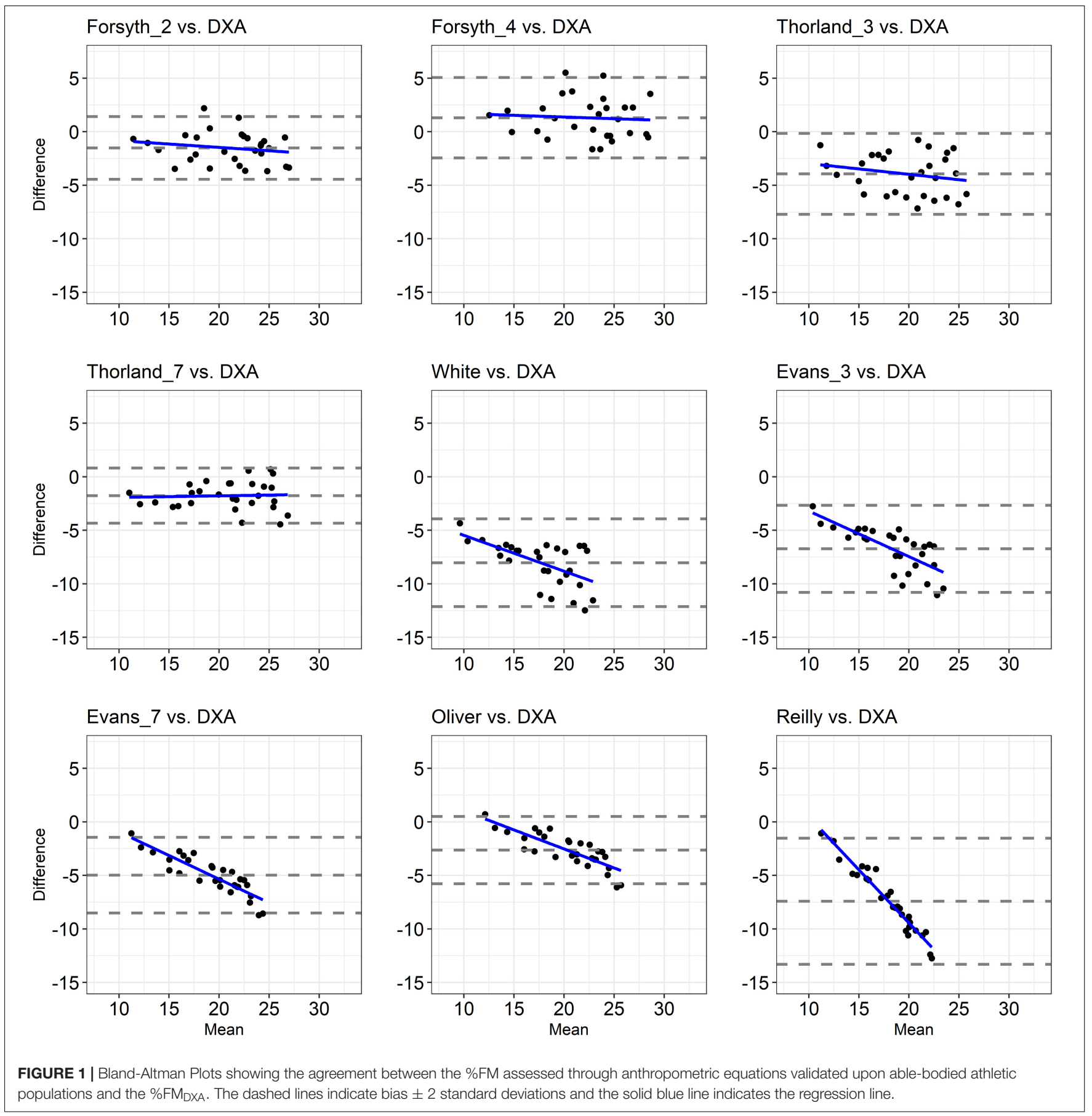

equations validated in non-athletic healthy populations (Sloan and Weir, 1970; Durnin and Womersley, 1974; Lean et al., 1996; Gallagher et al., 2000; Pongchaiyakul et al., 2005) systematically underestimated the $\% \mathrm{FM}_{\text {DXA }}$ with a mean bias ranging from $-2.1 \%$ in the equation by Sloan and Weir to $-9.0 \%$ in the equation of Lean et al. It is important to underline that the study sample of Willems and colleagues (Willems et al., 2015) was composed of seven wheelchair-game athletes who were "wheelchair independent during non-sport activities"; five of them had unilateral lower limb amputation and two had lower limb deficiencies. It is interesting to note that the mean bias found in the present study for the equation by Durnin and Womersley (0.51\%, non-significant) was lower than that found in the study by Willems and colleagues $(-4.2 \%$, statistically significant). This may be due to the fact that our study sample was homogeneous for the type of physical impairment (i.e., all athletes had unilateral lower limb amputation). Accordingly, it can be supposed that, in athletes with unilateral lower limb amputation only, the Durnin and Womersley equation may be more accurate in 

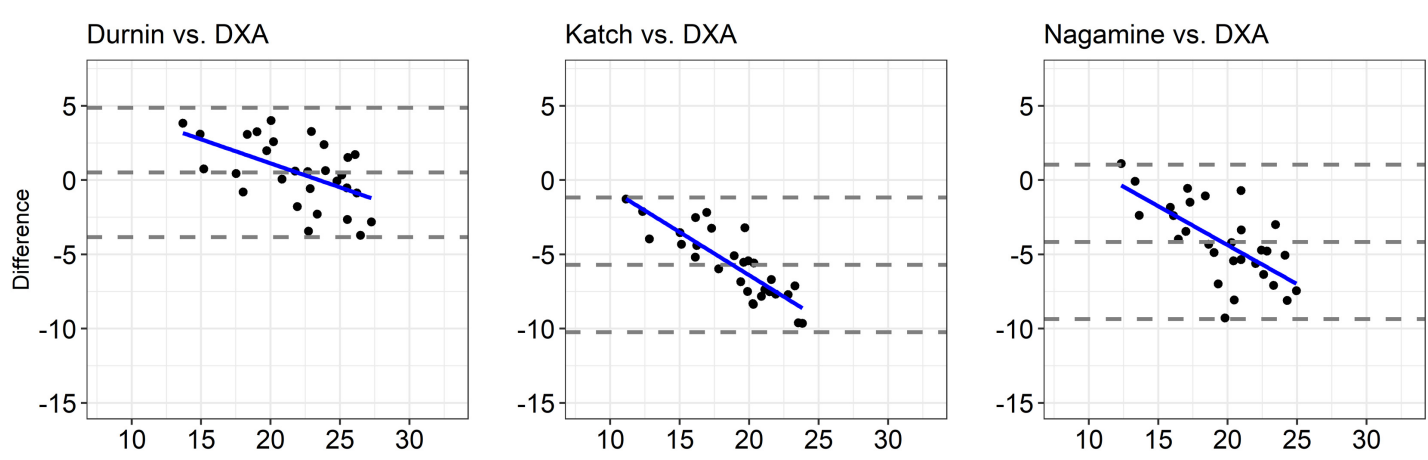

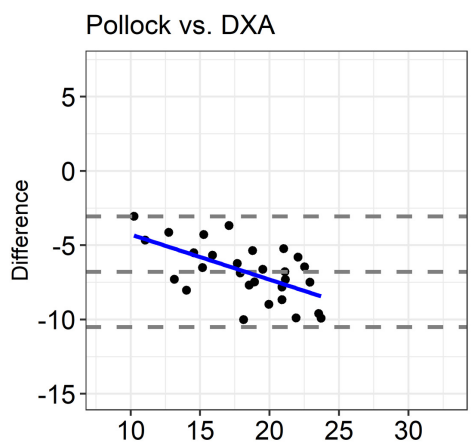

\section{Sloan vs. DXA}

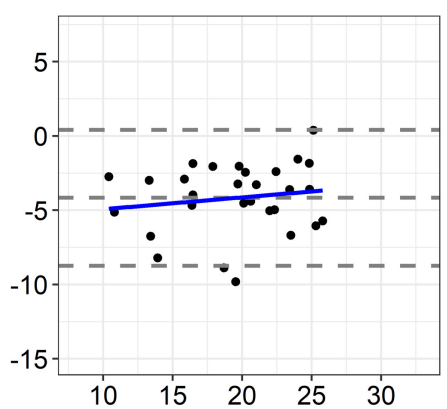

Eston vs. DXA

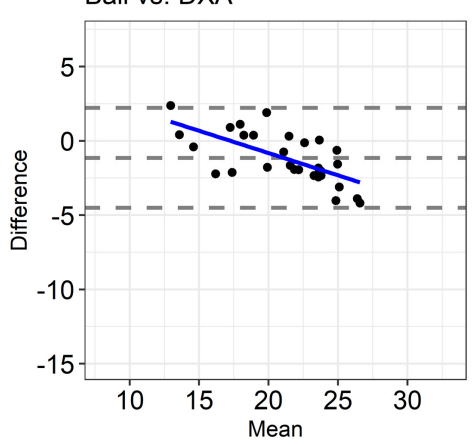

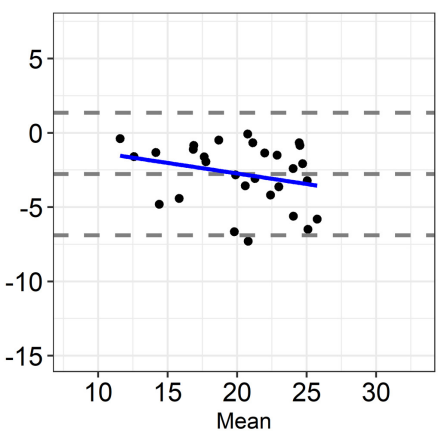

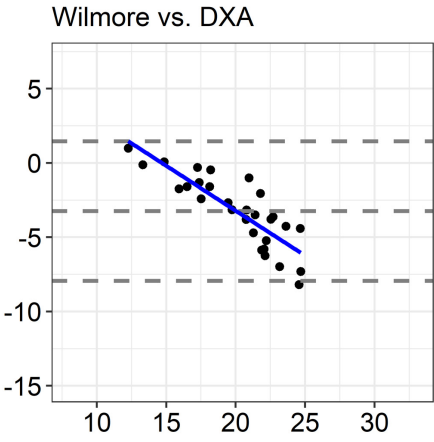

O'Connor vs. DXA

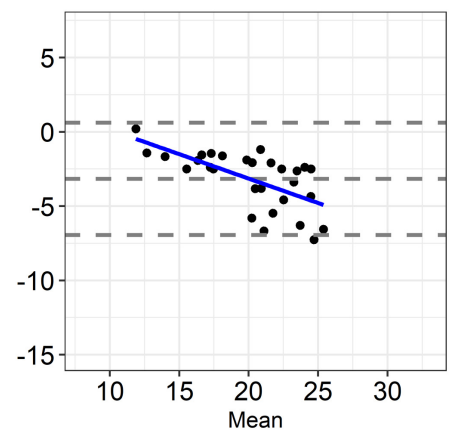

FIGURE 2 | Bland-Altman Plots showing the agreement between the \%FM assessed through anthropometric equations validated upon able-bodied non-athletic populations and the \%FM $M_{D X A}$. The dashed lines indicate bias \pm 2 standard deviations and the solid blue line indicates the regression line.

predicting the $\% \mathrm{FM}_{\mathrm{DXA}}$ than in athletes with different types of physical impairment.

Proportional bias in most comparisons between the \%FM $\mathrm{FXA}_{\mathrm{DA}}$ and the considered anthropometric equations suggests that the accuracy of the anthropometric equations is affected by the value of $\% \mathrm{FM}_{\mathrm{DXA}}$. Accordingly, anthropometric equations are more inaccurate in athletes with higher values of $\% \mathrm{FM}_{\mathrm{DXA}}$. It is important to take in mind that athletes in this study had values of $\% \mathrm{FM}_{\mathrm{DXA}}$ ranging from 11.8 to $28.7 \%$. This wide range of $\% \mathrm{FM}_{\mathrm{DXA}}$ values may be due to the fact that athletes competed in different adapted sports and their weekly amount of training for athletes ranges from 4 to $12 \mathrm{~h}$. Future research aimed at investigating the transferability of anthropometric equations, validated upon able-bodied populations, should also split up athletes according to the type of adapted sport they are practicing (e.g., endurance or team sports) and possibly also their range of $\% \mathrm{FM}$, for example grouping athletes with a $\% \mathrm{FM}$ lower than $15 \%$, between 15 and $20 \%$, between 20 and $25 \%$, greater than $25 \%$.

Taken together these results suggest that in athletes with unilateral lower limb amputation, the anthropometric equations validated upon able-bodied populations are inadequate in accurately predicting the $\% \mathrm{FM}_{\mathrm{DXA}}$, regardless of whether they have been validated in athletes or in non-athletes. Accordingly, these results underline the need for anthropometric equations for estimating the \%FM in this specific athletic population.

This study represents the first attempt to develop populationspecific anthropometric equations to predict the $\% \mathrm{FM}_{\mathrm{DXA}}$ in athletes with unilateral lower limb amputation. The developed equations using four skinfold thicknesses (i.e., anterior thigh, abdominal, subscapular, and axillary) and the sum of 9 skinfolds as predictors are able to predict more than $93 \%$ of total 
variance in $\% \mathrm{FM}_{\mathrm{DX}}$ with a small $\mathrm{SEE}$ (about $1 \%$ for both) and a large effect size $\left(f^{2}>13.1\right)$. Moreover, repeated crossvalidation analysis highlighted a good predictive performance of both proposed equations. Accordingly, the anthropometric equations developed in the current study accurately estimate the $\% \mathrm{FM}_{\mathrm{DXA}}$ and can therefore be used as a field tool to assess the \%FM in white male adult athletes with unilateral lower limb amputation. Moreover, they may even represent a useful tool for clinicians, nutritionist, sport doctors and physical conditioners to get important information about the nutritional status of their athletes.

This study has some limits to be mentioned. A first limitation is the small sample size. However, it is important to consider that this study deals with a highly specific population (i.e., athletes with unilateral lower limb amputation) making it difficult to recruit a large number of participants especially when they are required to travel in order to reach the site of data collection (e.g., to undergo laboratory tests). A second limit of the study was the limited number of measured anthropometric variables, which prevented the use of some anthropometric equations which could be applied in this population (e.g., Kanellakis et al., 2017). Third, the provided anthropometric equations were only cross-validated. Accordingly, future research is needed to validate the anthropometric equation developed in this study in independent samples of athletes with unilateral lower limb amputation. Fourth, we did not consider the type of sport practiced by athletes. Future research is advocated to provide sport-specific anthropometric equations for the different populations of athletes with unilateral lower limb amputation.

In this study there are also some important strengths to underline. First, we used DXA as the reference technique to provide an accurate measure of \%FM. DXA measurements are greatly reproducible and the validity of this method has been previously demonstrated also in athletes with a physical impairment (Keil et al., 2014). Second, this is the first study with such a relatively large number of athletes $(n=29)$ with the same type and severity of physical impairment (i.e., unilateral lower limb amputation) and homogeneous for gender, age group and race. Third, in this study we assessed the ability of a large number ( $n=18$ ) of anthropometric equations in predicting the \%FM $\mathrm{DXA}_{\mathrm{DA}}$, which had been validated upon both athletes and non-athletes.

In conclusion, this study filled a knowledge gap in the literature by showing that the available anthropometric equations derived from able-bodied populations (both athletic and nonathletic) are inaccurate in athletes with unilateral lower limb amputation in predicting the $\% \mathrm{FM}_{\mathrm{DXA}}$. This further underlines the need for impairment-specific anthropometric equations

\section{REFERENCES}

Anderson, W. L., Wiener, J. M., Khatutsky, G., and Armour, B. S. (2013). Obesity and people with disabilities: the implications for health care expenditures. Obesity 21, E798-E804. doi: 10.1002/oby.20531

Bacchi, E., Cavedon, V., Zancanaro, C., Moghetti, P., and Milanese, C. (2017). Comparison between dual-energy X-ray absorptiometry and skinfold thickness in assessing body fat in overweigh/obese adult patients with type-2 diabetes. Sci. Rep. 7:17424. doi: 10.1038/s41598-017-17788-y to estimate body composition in athletes with a physical impairment. As a first step toward this aim, this study produced two anthropometric equations based on skinfold thickness measurements to estimate the $\% \mathrm{FM}_{\mathrm{DXA}}$ in athletes with unilateral lower limb amputation. Nutritionists, clinicians and sports professionals will therefore benefit from using these proposed predictive equations as a rapid, non-invasive tool for assessing and monitoring body composition in athletes with unilateral lower limb amputation.

\section{DATA AVAILABILITY STATEMENT}

The raw data supporting the conclusions of this article will be made available by the authors, without undue reservation.

\section{ETHICS STATEMENT}

The studies involving human participants were reviewed and approved by the Institutional Review Board of the University of Verona. The patients/participants provided their written informed consent to participate in this study.

\section{AUTHOR CONTRIBUTIONS}

VC and CM conceived and designed the experiments. VC performed the experiments. MS and VC analyzed the data and conducted formal analysis. VC and CM wrote the manuscript with support from CZ. MV, CZ, and CM supervised and validated. All authors provided critical feedback and helped shape the research, analysis and manuscript.

\section{ACKNOWLEDGMENTS}

We gratefully acknowledge the kind contribution of the athletes for their kind cooperation. We especially thank Asia Facin for her help with data collection.

\section{SUPPLEMENTARY MATERIAL}

The Supplementary Material for this article can be found online at: https://www.frontiersin.org/articles/10.3389/fphys. 2020.620040/full\#supplementary-material

Ball, S. D., Altena, T. S., and Swan, P. D. (2004). Comparison of anthropometry to DXA: a new prediction equation for men. Eur. J. Clin. Nutr. 58, 1525-1531. doi: 10.1038/sj.ejcn.1602003

Bland, J. M., and Altman, D. G. (2012). Agreed statistics: measurement method comparison. Anesthesiology 116, 182-185. doi: 10.1097/ALN. 0b013e31823d7784

Cavedon, V., Zancanaro, C., and Milanese, C. (2015). Physique and performance of young wheelchair basketball players in relation with classification. PLoS One 10:e0143621. doi: 10.1371/journal.pone.0143621 
Cavedon, V., Zancanaro, C., and Milanese, C. (2018a). Anthropometry, body composition, and performance in sport-specific field test in female wheelchair basketball players. Front. Physiol. 9:568. doi: 10.3389/fphys.2018. 00568

Cavedon, V., Zancanaro, C., and Milanese, C. (2018b). Anthropometric prediction of DXA-measured body composition in female team handball players. PeerJ 6:e5913. doi: 10.7717/peerj.5913

Cicchetti, D. V. (1994). Guidelines, criteria, and rules of thumb for evaluating normed and standardized assessment instruments in psychology. Psychol. Assess. 6, 284-290. doi: 10.1037/1040-3590.6.4.284

Cohen, J. (1988). Statistical Power Analysis for the Behavioral Sciences. Hillsdale, NJ: L. Erlbaum Associates. doi: 10.4324/9780203771587

Durnin, J. V., and Womersley, J. (1974). Body fat assessed from total body density and its estimation from skinfold thickness: measurements on 481 men and women aged from 16 to 72 years. Br. J. Nutr. 32, 77-97. doi: 10.1079/ bjn 19740060

Eston, R. G., Rowlands, A. V., Charlesworth, S., Davies, A., and Hoppitt, T. (2005). Prediction of DXA-determined whole body fat from skinfolds: importance of including skinfolds from the thigh and calf in young, healthy men and women. Eur. J. Clin. Nutr. 59, 695-702. doi: 10.1038/sj.ejcn.1602131

Evans, E. M., Rowe, D. A., Misic, M. M., Prior, B. M., and Arngrímsson, S. A. (2005). Skinfold prediction equation for athletes developed using a four-component model. Med. Sci. Sports Exerc. 37, 2006-2011. doi: 10.1249/01.mss.0000176682. $54071.5 \mathrm{c}$

Faul, F. (2009). Statistical Power Analyses Using $G^{*}$ Power 3.1: Tests for Correlation and Regression Analyses | SpringerLink [WWW Document]. Available online at: https://link.springer.com/article/10.3758/BRM.41.4.1149 (accessed September 10, 2020).

Fisher, R. A. (1950). Statistical Methods for Research Workers (Ch.7), 11th Edn. Edinburgh: Oliver and Boyd.

Flueck, J. L. (2020). Body Composition in Swiss Elite Wheelchair Athletes. Front. Nutr. 7:1. doi: 10.3389/fnut.2020.00001

Forsyth, H. L., and Sinning, W. E. (1973). The anthropometric estimation of body density and lean body weight of male athletes. Med. Sci. Sports 5, 174-180.

Gallagher, D., Heymsfield, S. B., Heo, M., Jebb, S. A., Murgatroyd, P. R., and Sakamoto, Y. (2000). Healthy percentage body fat ranges: an approach for developing guidelines based on body mass index. Am. J. Clin. Nutr. 72, 694-701. doi: 10.1093/ajcn/72.3.694

Goosey-Tolfrey, V., Keil, M., Brooke-Wavell, K., and de Groot, S. (2016). A comparison of methods for the estimation of body composition in highly trained wheelchair games players. Int. J. Sports. Med. 37, 799-806. doi: 10.1055/ s-0042-104061

Harper, W. V. (2014). "Reduced major axis regression: teaching alternatives to least squares," in Sustainability in Statistics Education. Proceedings of the Ninth International Conference on Teaching Statistics (ICOTS9, eds K. Makar, B. de Sousa, and R. Gould (Flagstaff, AZ: International Statistical Institute),

Heyward, V. H., and Wagner, D. R. (2004). Applied Body Composition Assessment, Second Edn. (Champaign, IL: Human Kinetics).

Hopkins, W. G. (2016). Internet Society for Sports Science. A Scale of Magnitude for Effect Statistics [WWW Document]. Available online at: http://www.sportsci. org/resource/stats/index.html (accessed December 10, 2020).

International Paralympic Committee (2017). Annual Report 2017. Bonn: IPC.

International Paralympic Committee (2019). Annual Report 2019. Bonn: IPC

Iturricastillo, A., Granados, C., and Yanci, J. (2015). Changes in body composition and physical performance in wheelchair basketball players during a competitive season. J. Hum. Kinet. 48, 157-165. doi: 10.1515/hukin-2015-0102

Kanellakis, S., Skoufas, E., Khudokonenko, V., Apostolidou, E., Gerakiti, L., Andrioti, M. C., et al. (2017). Development and validation of two equations based on anthropometry, estimating body fat for the Greek adult population. Obesity 25, 408-416. doi: 10.1002/oby.21736

Katch, F. I., and McArdle, W. D. (1973). Prediction of body density from simple anthropometric measurements in college-age men and women. Hum. Biol. 45, 445-455.

Keil, M., Totosy de Zepetnek, J. O., Brooke-Wavell, K., and Goosey-Tolfrey, V. L. (2014). Measurement precision of body composition variables in elite wheelchair athletes, using dual-energy X-ray absorptiometry. Eur. J. Sport. Sci. 16, 65-71. doi: 10.1080/17461391.2014.966763

Lean, M. E., Han, T. S., and Deurenberg, P. (1996). Predicting body composition by densitometry from simple anthropometric measurements. Am. J. Clin. Nutr. 63, 4-14. doi: 10.1093/ajcn/63.1.4

Lin, L. I.-K. (1989). A concordance correlation coefficient to evaluate reproducibility. Biometrics 45, 255-268. doi: 10.2307/2532051

Lohman, T. G., Roche, A. F., and Martorell, R. (eds) (1988). Anthropometric Standardization Reference Manual. (Champaign, IL: Human Kinetics)

Nagamine, S., and Suzuki, S. (1964). Anthropometry and body composition of japanese young men and women. Hum. Biol. 36, 8-15.

Nana, A., Slater, G. J., Stewart, A. D., and Burke, L. M. (2015). Methodology review: using dual-energy X-ray absorptiometry (DXA) for the assessment of body composition in athletes and active people. Int. J. Sport. Nutr. Exerc. Metab. 25, 198-215. doi: 10.1123/ijsnem.2013-0228

O’Connor, D. P., Bray, M. S., McFarlin, B. K., Sailors, M. H., Ellis, K. J., and Jackson, A. S. (2010). Generalized equations for estimating DXA percent fat of diverse young women and men: the TIGER study. Med. Sci. Sports. Exerc. 42, 1959-1965. doi: 10.1249/MSS.0b013e3181dc2e71

Oliver, J. M., Lambert, B. S., Martin, S. E., Green, J. S., and Crouse, S. F. (2012). Predicting football players' dual-energy $\mathrm{x}$-ray absorptiometry body composition using standard anthropometric measures. J. Athl. Train. 47, 257-263. doi: 10. 4085/1062-6050-47.3.12

Ozkan, A., Kayıhan, G., Köklü, Y., Ergun, N., Koz, M., Ersöz, G., et al. (2012). The relationship between body composition, anaerobic performance and sprint ability of amputee soccer players. J. Hum. Kinet. 35, 141-146. doi: 10.2478/ v10078-012-0088-3

Pollock, M. L., Hickman, T., Kendrick, Z., Jackson, A., Linnerud, A. C., and Dawson, G. (1976). Prediction of body density in young and middle-aged men. J. Appl. Physiol. 40, 300-304. doi: 10.1152/jappl.1976.40. 3.300

Pongchaiyakul, C., Kosulwat, V., Rojroongwasinkul, N., Charoenkiatkul, S., Thepsuthammarat, K., Laopaiboon, M., et al. (2005). Prediction of percentage body fat in rural thai population using simple anthropometric measurements. Obes. Res. 13, 729-738. doi: 10.1038/oby.2005.82

Reilly, T., George, K., Marfell-Jones, M., Scott, M., Sutton, L., and Wallace, J. A. (2009). How well do skinfold equations predict percent body fat in elite soccer players? Int. J. Sports. Med. 30, 607-613. doi: 10.1055/s-0029-120 2353

Sherk, V. D., Bemben, M. G., and Bemben, D. A. (2010). Interlimb muscle and fat comparisons in persons with lower-limb amputation. Arch. Phys. Med. Rehabil. 91, 1077-1081. doi: 10.1016/j.apmr.2010.04.008

Simim, M. A. M., Silva, B. V. C., Marocolo Júnior, M., Mendes, E. L., de Mello, M. T., and da Mota, G. R. (2013). Anthropometric profile and physical performance characteristic of the Brazilian amputee football (soccer) team. Motriz 19, 641-648. doi: 10.1590/S1980-65742013000300016

Siri, W. E. (1961). "Body volume measurement by gas dilution," in Techniques for Measuring Body Composition, eds J. Brozek and A. Henschel (Washington, DC: National Academy of Sciences), 108-117.

Sloan, A. W. (1967). Estimation of body fat in young men. J. Appl. Physiol. 23, 311-315. doi: 10.1152/jappl.1967.23.3.311

Sloan, A. W., and Weir, J. B. (1970). Nomograms for prediction of body density and total body fat from skinfold measurements. J. Appl. Physiol. 28, 221-222. doi: 10.1152/jappl.1970.28.2.221

Sutton, L., Wallace, J., Goosey-Tolfrey, V., Scott, M., and Reilly, T. (2009). Body composition of female wheelchair athletes. Int. J. Sports Med. 30, 259-265. doi: $10.1055 / \mathrm{s}-0028-1105941$

Thorland, W. G., Johnson, G. O., Tharp, G. D., Housh, T. J., and Cisar, C. J. (1984). Estimation of body density in adolescent athletes. Hum. Biol. 56, 439-448.

Wasser, J. G., Vincent, K. R., Herman, D. C., and Vincent, H. K. (2020). Potential lower extremity amputation-induced mechanisms of chronic low back pain: role for focused resistance exercise. Disabil. Rehabil. 42, 3713-3721. doi: 10. 1080/09638288.2019.1610507

White, J., Mayhew, J. L., and Piper, F. C. (1980). Prediction of body composition in college football players. J. Sports Med. Phys. Fitness 20, 317-324. 
Willems, A., Paulson, T. A. W., Keil, M., Brooke-Wavell, K., and Goosey-Tolfrey, V. L. (2015). Dual-energy X-ray absorptiometry, skinfold thickness, and waist circumference for assessing body composition in ambulant and non-ambulant wheelchair games players. Front. Physiol. 6:356. doi: 10.3389/fphys.2015. 00356

Wilmore, J. H., and Behnke, A. R. (1970). An anthropometric estimation of body density and lean body weight in young women. Am. J. Clin. Nutr. 23, 267-274. doi: $10.1093 /$ ajcn/23.3.267

World Amputee Football Federation (2005). Laws and Rules Governing Amputee Football Play and Players. Available online at: https://fispes.it/kp/uploads/lawsof-the-game-2017.pdf (accessed December 3, 2020).
Conflict of Interest: The authors declare that the research was conducted in the absence of any commercial or financial relationships that could be construed as a potential conflict of interest.

Copyright (c) 2020 Cavedon, Sandri, Venturelli, Zancanaro and Milanese. This is an open-access article distributed under the terms of the Creative Commons Attribution License (CC BY). The use, distribution or reproduction in other forums is permitted, provided the original author(s) and the copyright owner(s) are credited and that the original publication in this journal is cited, in accordance with accepted academic practice. No use, distribution or reproduction is permitted which does not comply with these terms. 